\title{
ELECTRICAL AND MECHANICAL PROPERTIES OF CU-CNT NANOCOMPOSITES SINTERED BY MICROWAVE TECHNIQUE
}

\author{
Marjan Darabi, Masoud Rajabi * \\ ${ }^{1}$ Department of Materials Science and Engineering, Faculty of \\ Technology and Engineering, Imam Khomeini International University \\ (IKIU), Qazvin, Iran
}

Received 02.08.2017

Accepted 23.12.2017

\begin{abstract}
In this research, multiwall carbon nanotubes were dispersed in a copper matrix using a planetary ball mill. The mixed powders were compacted using a uniaxial hydraulic presser. A novel method of microwave sintering was applied to consolidate $\mathrm{Cu}-\mathrm{CNT}$ nanocomposites Conventional sintering method was also used to sinter samples to investigate the effects of applied methods on the properties of the sample. Sintering time was reduced to $20 \mathrm{~min}$ using microwave sintering method. The morphology and phase analysis of nanocomposites were studied by FESEM and XRD. The physical and mechanical properties of $\mathrm{Cu}-\mathrm{CNT}$ nanocomposites were characterized using electrical conductivity, bending strength, and micro-hardness. The results show that the mechanical properties of $\mathrm{Cu}-\mathrm{CNT}$ nanocomposites are improved significantly by microwave route. The optimum hardness and bending strength were obtained for 4 vol. \% CNT as an optimum amount of reinforcement.

Keywords: microwave processing; $\mathrm{Cu}-\mathrm{CNT}$ nanocomposites; mechanical properties.

\section{Introduction}

Copper is known as one the most effective materials used for thermal and electronic applications such as in rocket engines [1] and high-voltage switches [2] for many years, although $\mathrm{Cu}$ usage is limited in these applications due to its low mechanical strength [2].

A wide range of researchers have been dedicated to the progress of polymer [3-5] and ceramic [6-8] reinforced with carbon nanotubes (CNTs). In addition, the combination of CNT with metal matrix [9-12] has recently become the main topic worth
\end{abstract}

\footnotetext{
* Corresponding author: Masoud Rajabi, m.rajabi@eng.ikiu.ac.ir,
} masoudrajabi@yahoo.com 
investigating. Last several decades, $\mathrm{Cu}$ composites have been studied and applied in a wide range of industries.

The invention of CNT by Iijima [13] in 1991 revolutionized in the areas of technology and materials. Previous researchers have showed that CNTs (SWCNTs and MWCNTs) possess excellent properties such as extremely-high elastic modulus of 0.5-2 TPa [14-17], tensile strength of 20-150 GPa [18-21], thermal conductivity (3000-6000 $\mathrm{W} / \mathrm{mK})$ [22-24], low coefficient thermal expansion $\left(\sim 0 \times 10^{-6} 1 / \mathrm{K}\right)$ [25-26] along with self-lubricant [1] and high flexibility [14, 27].

In literature, various synthesis techniques for producing metal matrix composites (MMCs) were employed, which are categorized into two main groups: liquid state processing (e.g. casting, and liquid infiltration), and solid-state processing, based on powder metallurgy techniques. Liquid state processing is an effective technique to fabricate MMCs; however, the main disadvantages are the difficult distribution of reinforcement and high reactivity of the matrix with reinforcement, which occurs at high temperatures [28]. Powder metallurgy has been considered as a prevalent method to produce MMCs with less wasting materials and machining operations [29-31].

One of the most important issues in conventional sintering of nanocomposites is the grain growth, which is an intrinsic problem in the densification of nanocomposites. Advanced sintering techniques have been attracted to restrict the grain growth such as spark plasma sintering (SPS), hot isostatic pressing (HIP), or high presser torsion (HPT). The grain growth inhibition during sintering is expected to achieve preferable mechanical properties such as higher hardness and strength that are attributed to finer the grain sizes [32, 33].

There are fundamentally several differences between microwave and conventional sintering techniques. In microwave sintering, oscillations of free electrons at high frequency $(\sim 2.45-28 \mathrm{GHz})$ created by microwave field result in fast volumetric heating [33-35]. This fast sintering method improves the mechanical properties by maintaining a fine grain structure. In addition, microwave sintering has major advantages including a decline in thermal shock from the surface to core of the structure by effective and rapid heating, higher energy efficiency rate, uniformly heating, and reducing the time for grain growth and cost savings [36]. Recently, various reports have indicated that MMCs can be successfully fabricated by microwave sintering [37-39].

Rajkumar and Aravindan have shown an improvement in hardness and tribological properties of $\mathrm{Cu}-\mathrm{CNTs}$ composites sintered by microwave route [37]. Akeem et al. have presented a significant increase in hardness and compressive strength of CNT reinforcement for AZ61 Magnesium Alloys [40]. For better clarification, this work presents the results of mechanical and electrical properties of $\mathrm{Cu}$-CNT composites sintered by microwave technique. Also, optimum sintering time and amount of CNT to produce nanocomposite samples by the microwave sintering method have been reported. In addition, a remarkable comparison has been made between conventional and microwave sintering methods, indicating that long synthesis time of samples by the conventional method can be replaced with a shorter time (comparatively, one-sixth of the time) by microwave method. 


\section{Experimental procedure}

\section{Materials}

Copper powder (provided by PMC of Iran) with $99.9 \%$ purity and grain size of less than $25 \mu \mathrm{m}$ as the matrix material, multi-walled carbon nanotubes with $20-30 \mathrm{~nm}$ diameter and purity level of $>95 \%$ as the reinforced material (prepared by US Nano of America) were used for this work. The SEM and TEM images of MWCNT are shown in Fig. 1 .

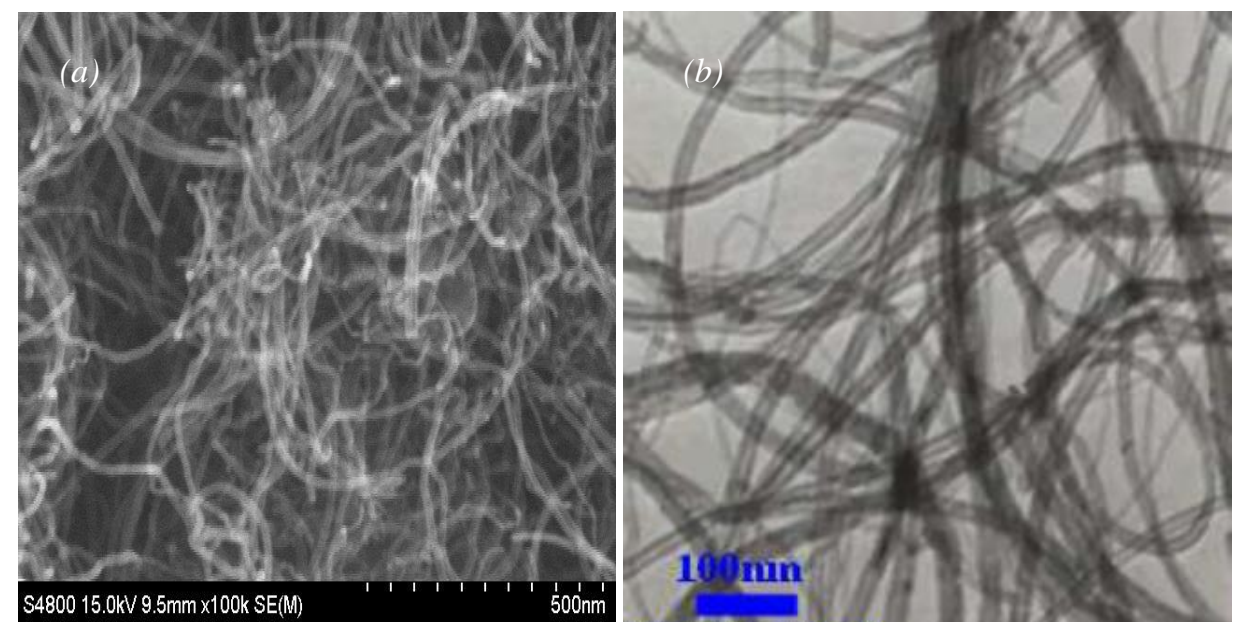

Fig. 1. Micrographs of MWCNT: (a) SEM and (b) TEM.

Copper powder was mixed with MWCNT at $120 \mathrm{rpm}$ in a planetary ball mill using a stainless-steel jar under argon atmosphere. The mixed powders were pressed into a uniaxial die of stainless steel at the pressure of $450 \mathrm{MPa}$. Microwave and conventional sintering methods were applied to sinter the compacted samples. In microwave processing method, the samples were immersed in $\mathrm{SiC}$ bed (which absorbs microwave and supplies necessary thermal energy for sintering) inside alumina crucibles and under Ar-atmosphere in a microwave oven $(900 \mathrm{~W}, 2.45 \mathrm{GHz}, \mathrm{LG}$ microwave oven). The sintering time for $\mathrm{Cu}-1$ vol. \% CNT nanocomposites samples were done at 10, 15, 20 and $25 \mathrm{~min}$. The other samples were sintered in a tube furnace under Ar-atmosphere at $900{ }^{\circ} \mathrm{C}$ temperature for $2 \mathrm{~h}$.

\section{Characterization}

The Archimedes method was used to measure the density of the sintered specimens according to ASTM B311. Vickers micro-hardness measurements were performed on the polished sample using an HVS-1000A automatic digital microhardness tester under a loading of $50 \mathrm{~g}$ and a dwell time of $10 \mathrm{~s}$ in accordance with the ASTM standard E92. The bending strength test was carried out using a Zwich RoaellZ100 universal testing machine with an initial strain of $0.5 \mathrm{~mm} / \mathrm{min}$ at room temperature (according to ASTM D790). The electrical conductivity of sintered samples was measured according to the international annealing copper standard (IACS \%) by Sigmore 100 testing machine. 
X-ray diffraction (XRD) analysis of the sintered samples was performed using a Xpert Philips Diffractometer $\left(\mathrm{Cu} \mathrm{k}_{\alpha}\right.$ radiation with $\left.\lambda=1.5404^{\circ} \mathrm{A}\right)$ with the voltage and current setting of $40 \mathrm{kV}$ and $30 \mathrm{~mA}$, respectively. In order to observe the microstructure of the nanocomposite samples, a field emission scanning electron microscope (FESEM) fitted with energy-dispersive X-ray spectroscopy (EDX) was used.

\section{Result and discussion}

Effect of microwave sintering time and CNT content

As shown in Fig. 2, the relative density of $\mathrm{Cu}-1$ vol. \% CNT nanocomposites samples increased with an increase in sintering time; however, at a longer heating time up to $25 \mathrm{~min}$, the relative density has a tendency to decrease. Therefore, the optimum heating time, which results in maximum relative density, was obtained to be $20 \mathrm{~min}$ in this work.

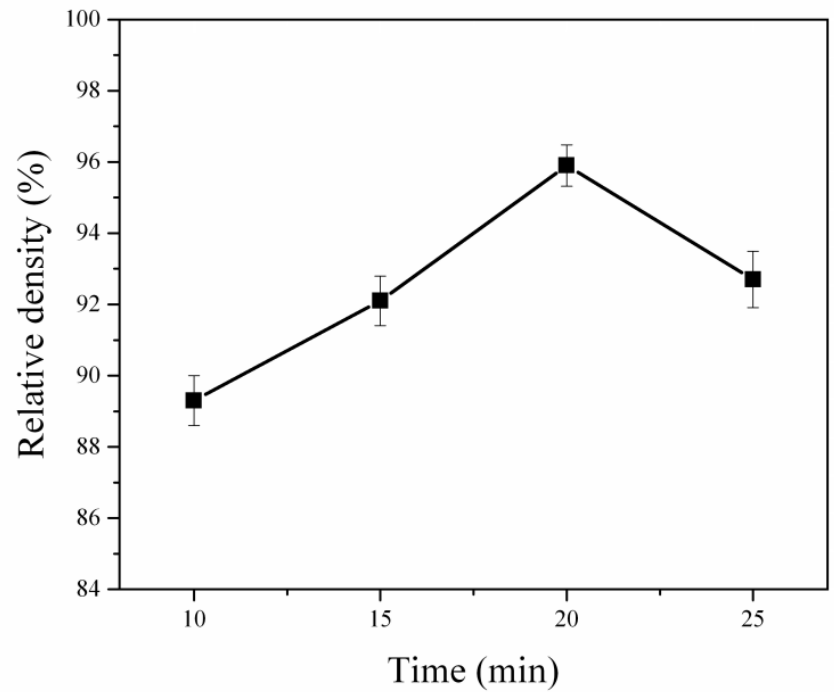

Fig. 2. Relative density as a function of the microwave sintering time.

Fig. 3 shows the micro-hardness and bending strength of $\mathrm{Cu}-1$ vol. \% CNT nanocomposite samples sintered at different times. 


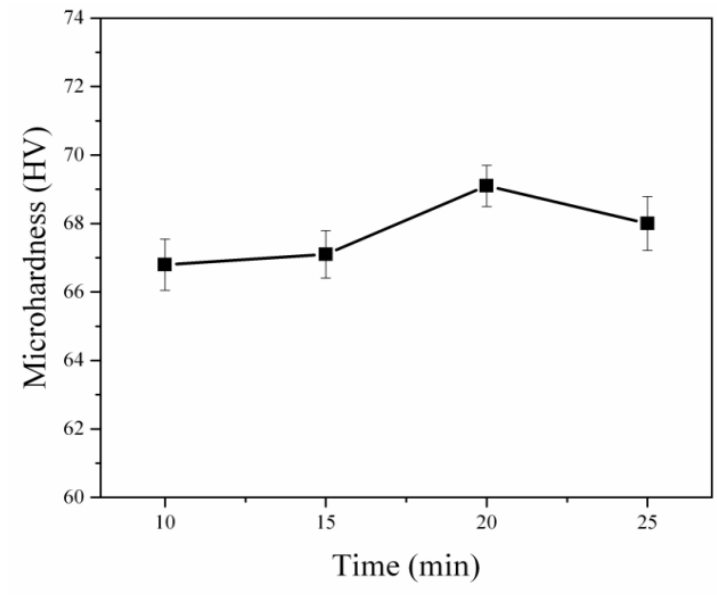

(a)

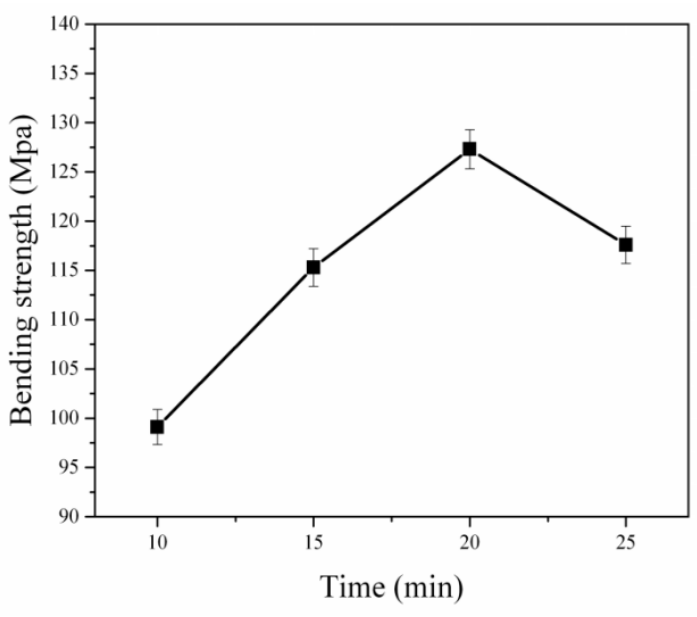

Fig. 3. a) Micro-hardness and b) bending strength as functions of sintering times using microwave route.

These mechanical properties were improved with the increase of the sintering time up to $20 \mathrm{~min}$, which is the result of the relatively higher density, as shown in Fig. 2. The maximum microhardness and bending strength were obtained at about 20 min of microwave sintering. As the sintering through microwave processing can generate the finer structure, the grain boundaries increase in the structure; accordingly, they restrict dislocation movements and lead to increase in the hardness and bending strength [40]. The finer structure can be observed through FESEM micrographs of nanocomposite at 20 min rather than $10 \mathrm{~min}$ (Fig. 4). However, micro-hardness and bending strength decreased for a further increment of time (i.e., up to $25 \mathrm{~min}$ ). This decrease could be related to the effect of grain growth (Fig. 4(c)) as well as the decline of the relative density of $\mathrm{Cu}-1$ vol. \% CNT nanocomposite, when samples were heated more than 20 min. As a result, according to Fig. 3, the optimum sintering time is $20 \mathrm{~min}$ for the samples sintered in the microwave oven. 

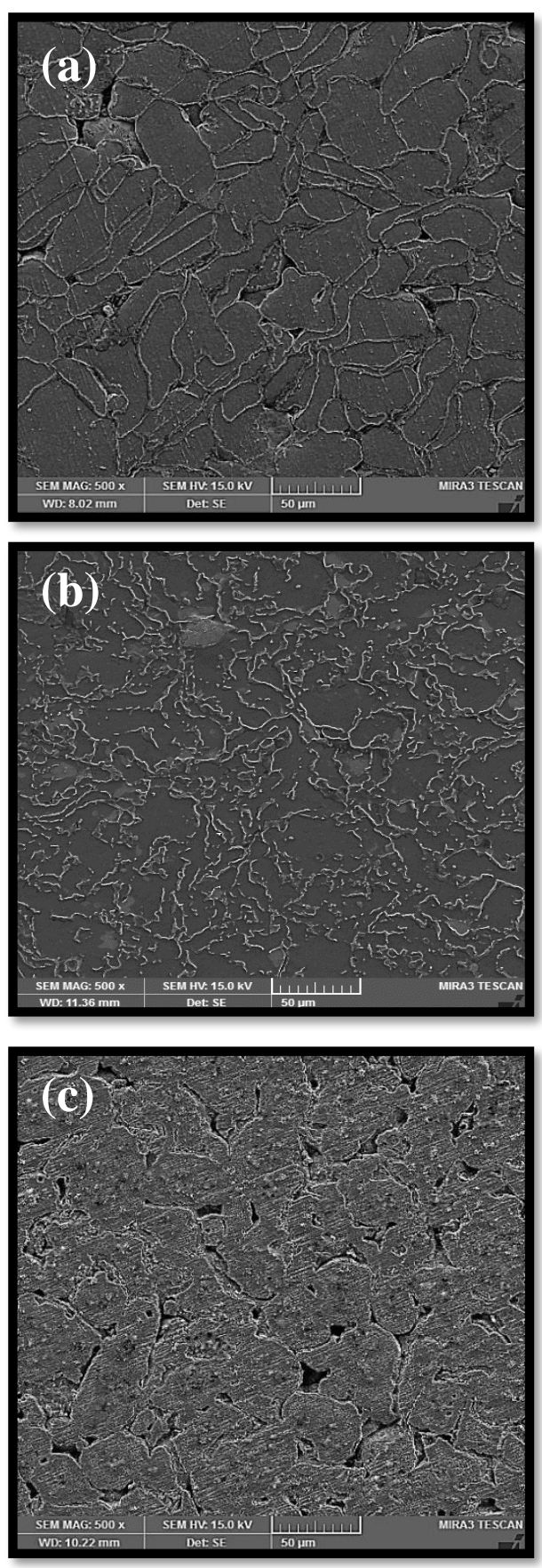

Fig. 4. FESEM images of $\mathrm{Cu}-1 \mathrm{vol}$. \% CNT nanocomposite samples sintered in a) $10 \mathrm{~min}$, b) $20 \mathrm{~min}$, and c) $25 \mathrm{~min}$. 
In the following, a comparison between conventional and microwave sintering techniques is made. The optimum sintering temperature and time for MMCs based on copper reinforced CNT were reported at $900^{\circ} \mathrm{C}$ and $2 \mathrm{~h}$, by previous researches [22, 4244]. Therefore, in this work, conventional sintering process was carried out at a sintering temperature of $900{ }^{\circ} \mathrm{C}$ for $2 \mathrm{~h}$, and the samples produced by microwave sintering method was selected for 20 min sintering time. The measured temperature was about $830{ }^{\circ} \mathrm{C}$ on the surface of samples.

Fig. 5 shows the relative densities of $\mathrm{Cu}-\mathrm{x} \% \mathrm{CNT}(\mathrm{x}=2,4,6$ vol. \%) nanocomposites using different sintering methods. The relative density decreases with an increase in CNT content in both methods.

This reduction could be related to the high volume of CNT agglomeration and porosity in the microstructure and lower density of CNT in the matrix.

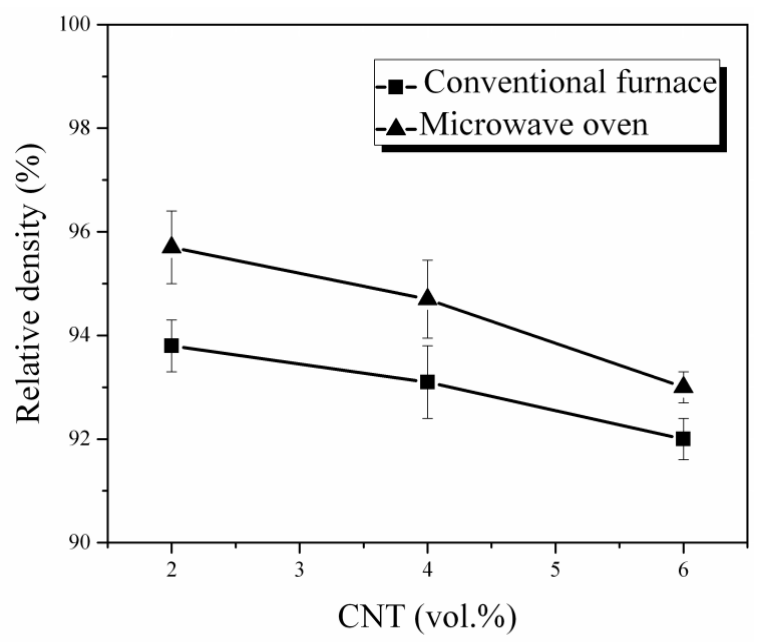

Fig. 5. Comparison of relative densities between $\mathrm{Cu}$-CNT nanocomposites produced using a conventional and microwave sintering.

Fig. 6 indicates the average of Vickers micro-hardness and bending strength as a function of CNT vol. \% in both methods. The blocking of the dislocation movement in the matrix is more effective in the presence of CNT; also, the matrix of the $\mathrm{Cu}-\mathrm{CNT}$ nanocomposites includes higher dislocation density due to the differences in thermal expansion coefficients of $\mathrm{Cu}$ and CNT, bringing about thermal mismatch stresses [45, 46] and high work-hardening rate. In comparison, nanocomposites produced by microwave-assisted sintering method have higher micro-hardness and bending strength values, which shows the improvement of the mechanical properties.

It is interesting to note that the average measurements of micro-hardness of $\mathrm{Cu}$ matrix without CNT were obtained as $58.4 \mathrm{HV}$ and $69.5 \mathrm{HV}$ by conventional and microwave sintering methods, respectively. In addition, values of bending strength were 124.0 MPa for conventional sintering method and 127.2 $\mathrm{MPa}$ for microwave sintering method.

A significant reduction in hardness and bending strength can be observed for the samples containing 6 vol. \% CNT in both methods due to large-volume agglomeration 
of the CNT and the presence of pores [47, 48] which could cause the bad effects on mechanical properties [49]. Nevertheless, compared with conventional sintering route, the hardness and bending strength of the samples produced by the microwave-assisted method are higher due to shorter sintering time and lower temperature, leading to the finer microstructure.

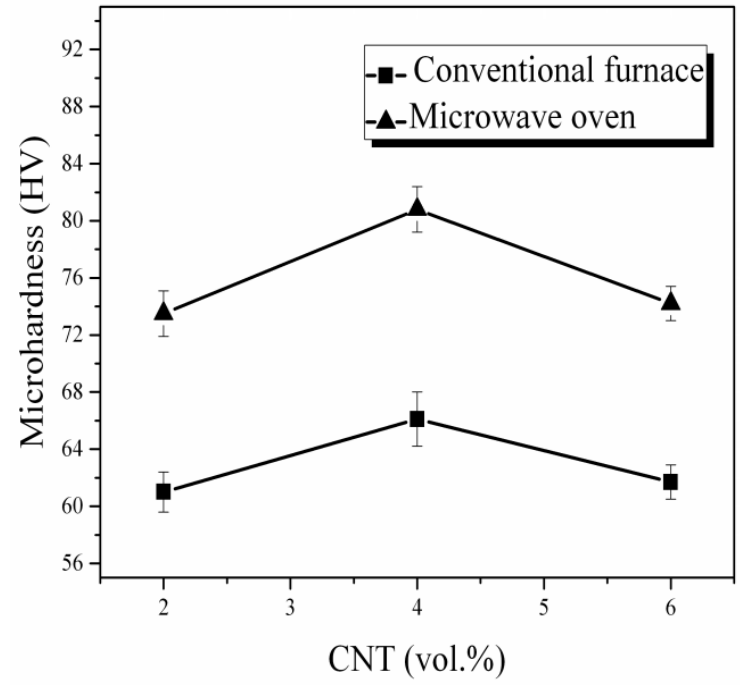

(a)

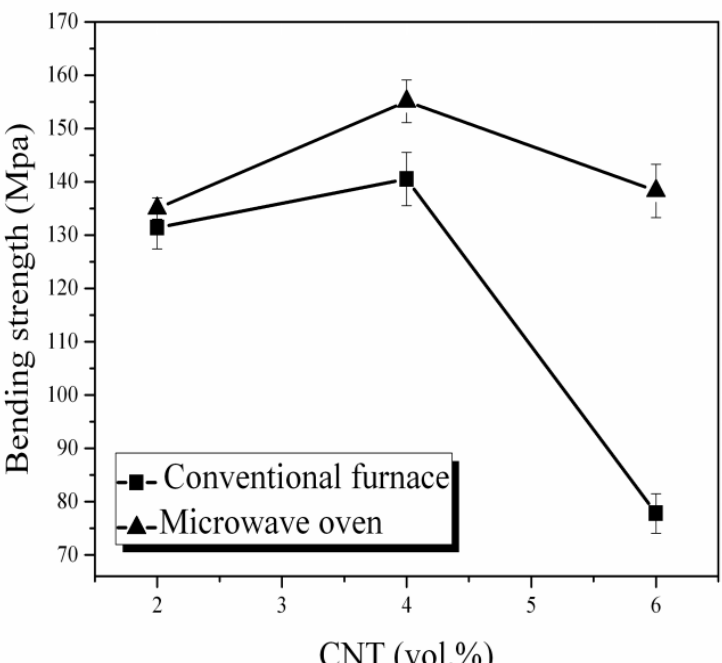

(b)

Fig. 6. Comparison of a) micro-hardness and b) bending strength between nanocomposites fabricated by the conventional and microwave sintering methods as a function of CNT vol. \%. 


\section{Electrical conductivity}

The electrical conductivity of $\mathrm{Cu}-\mathrm{CNT}$ nanocomposites fabricated by conventional and microwave sintering methods is presented in Fig. 7. There is a decrease in the electrical conductivity values with the increase of CNT in both methods. A significant reduction in electrical conductivity of the $\mathrm{Cu}-\mathrm{CNT}$ nanocomposites is related to the dispersion of $\mathrm{CNT}$ in the $\mathrm{Cu}$ grain boundaries, operating as barriers against electron mobility and causing conductivity decline. The specimens with a highvolume fraction of the CNT ( 6 vol. \% CNT) are likely to be less efficient in terms of carrier transport due to the existence of CNT clusters having larger grain-boundary per unit volume, resulting in lower carrier mobility and electrical conductivity decline.

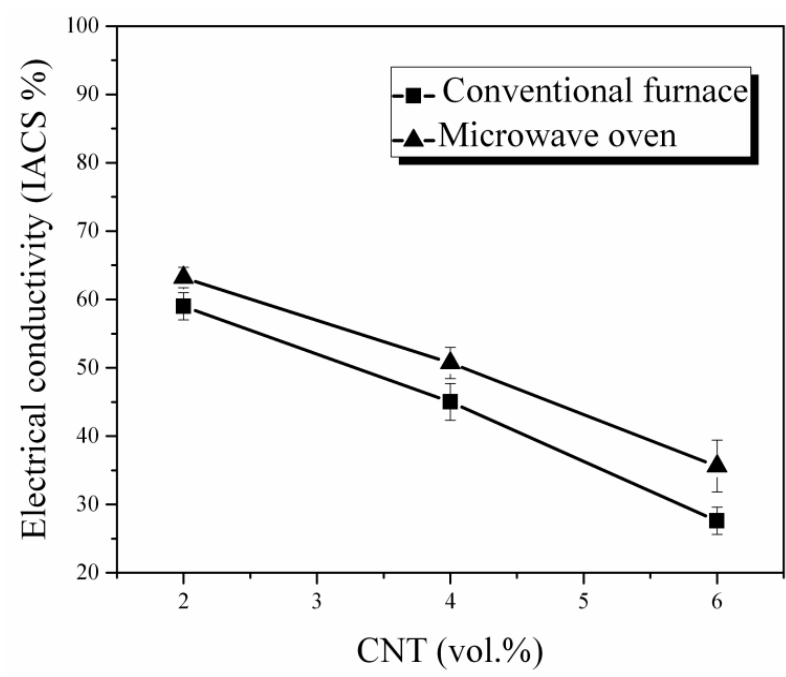

Fig. 7. Variation of the electrical conductivity of the Cu-CNT nanocomposites produced in the conventional tube furnace and microwave oven.

Fig. 5-7 indicate that higher density, hardness, bending strength, and electrical conductivity have been obtained for the $\mathrm{Cu}-\mathrm{CNT}$ nanocomposite samples produced by microwave sintering method, rather than by conventional sintering method.

The most significant difference between conventional and microwave sintering methods is the heating mechanism. By conventional sintering method, the heating is concentrated along the surface of the samples [50, 51]. On the other hand, by microwave sintering method, the materials absorb microwave energy and transform it into heat. The microwave heating pattern and higher heating rate with a shortened sintering time can generate the finer of grain size [50].

\section{Microstructure}

A comparison of nanocomposites microstructures containing 4 vol. \% CNT produced by both of the methods is shown in Fig. 8. The sample produced by microwave sintering has a finer microstructure and less porosity in compared to the sample produced by conventional sintering. 

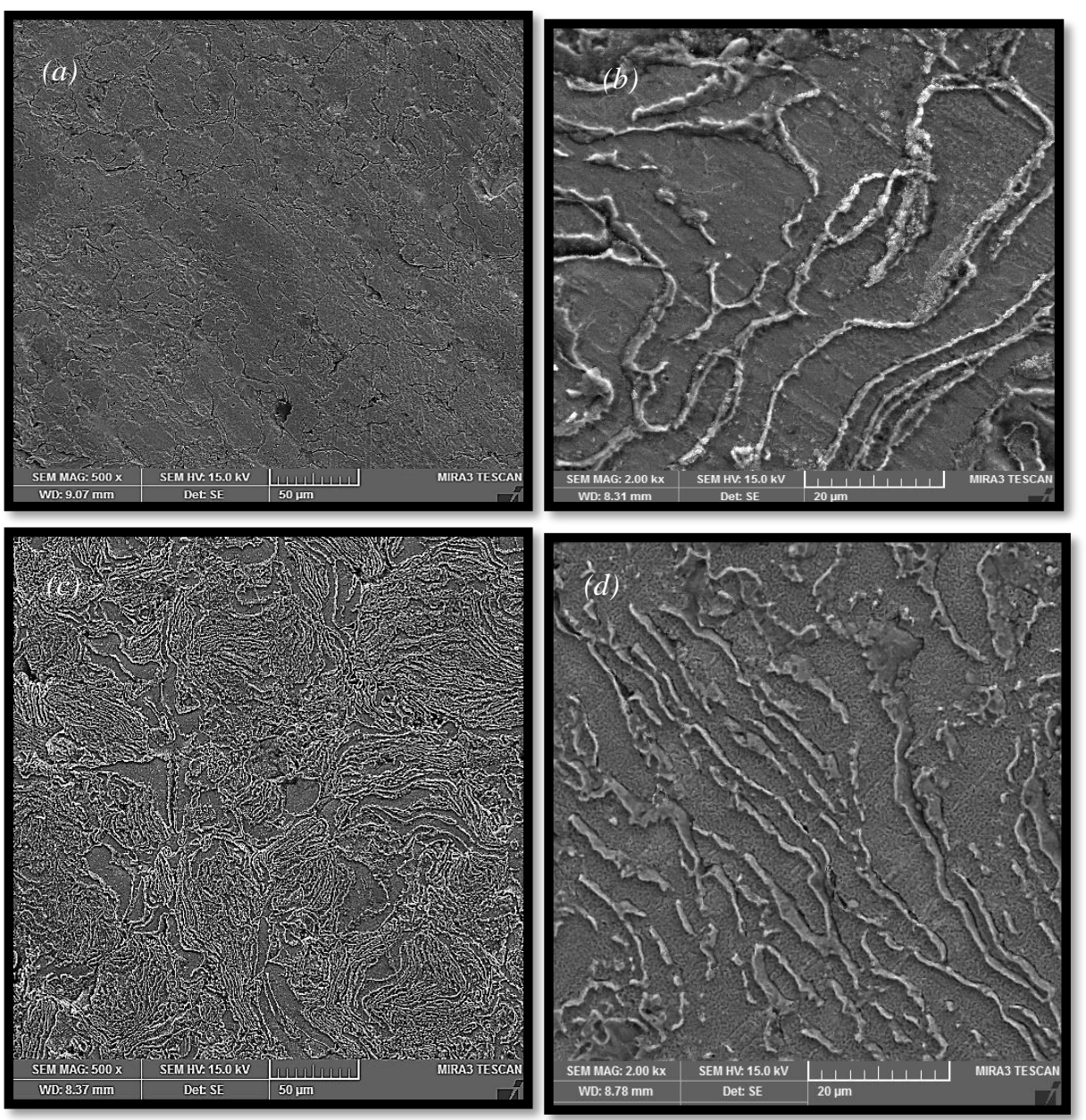

Fig. 8. FESEM images of Cu-4 vol. \% CNT nanocomposites samples sintered by a, b) conventional and $c, d$ ) microwave method.

The X-ray diffraction patterns of optimum samples (Cu-4 vol. \% CNT nanocomposites) produced by both methods are shown in Fig. 9. Three major peaks corresponding to FFC structure of copper exist in both patterns. The homogeneous dispersion of CNT in the matrix [52], less amount, and amorphous structure of CNT $[18,53]$ could be the reason for the absence of CNT peaks. The most significant difference in both of the patterns is that the intensity of XRD peaks. The low intensity of XRD peak of microwave sintered sample is observed, which are probably due to low sintering time and temperature preventing grain growth in the structure. In addition, copper oxide diffraction is not indicated in patterns, probably due to the very low amount of surface oxidation of copper. 


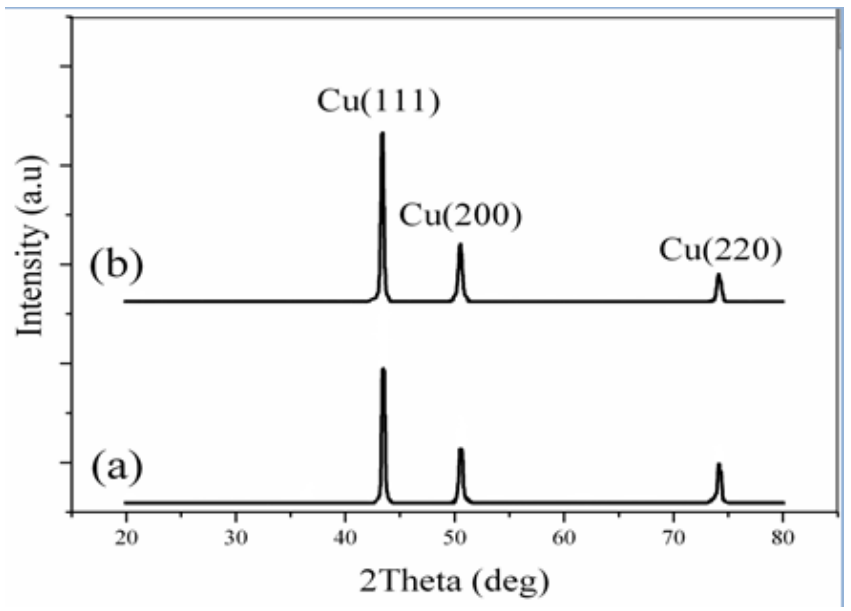

Fig. 9. XRD patterns of optimum samples sintered by a) microwave and b) conventional method.

Fig. 10 shows FESEM micrographs of microstructure and agglomerated region of CNT for microwave sintered $\mathrm{Cu}-6$ vol. \% CNT together with EDX analysis results focused on the CNT cluster. According to Fig. 10(a), point A is a region of agglomerated CNT that is rich in carbon $(\mathrm{C})$. Therefore, a reduction in micro-hardness and strength values in the sample containing 6 vol. \% CNT produced by microwave sintering method could be related to these agglomerations.

Fig. 11 shows MAP (SEM mapping) analysis images of $\mathrm{Cu}$ and $\mathrm{C}$ elements for Cu-6 vol. \% CNT nanocomposite produced by microwave sintering method. The images show a heterogeneous dispersion of $\mathrm{C}$ element in the matrix of nanocomposite which is related to the high CNT content in the nanocomposite. 

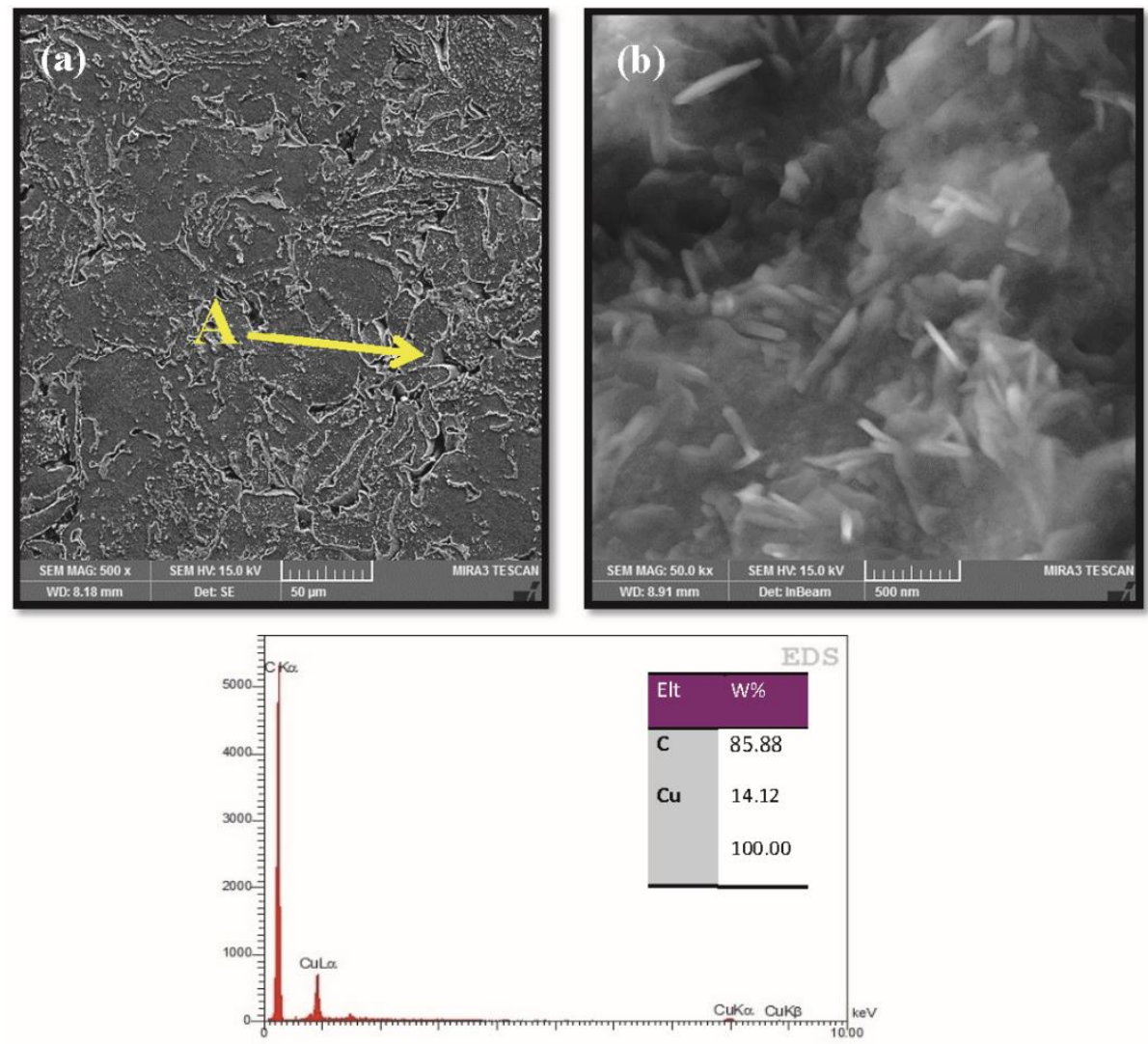

Fig. 10. FE-SEM micrographs of a) microstructure and b) agglomerated region of CNT with related EDX analysis of point A shown in the micrograph.
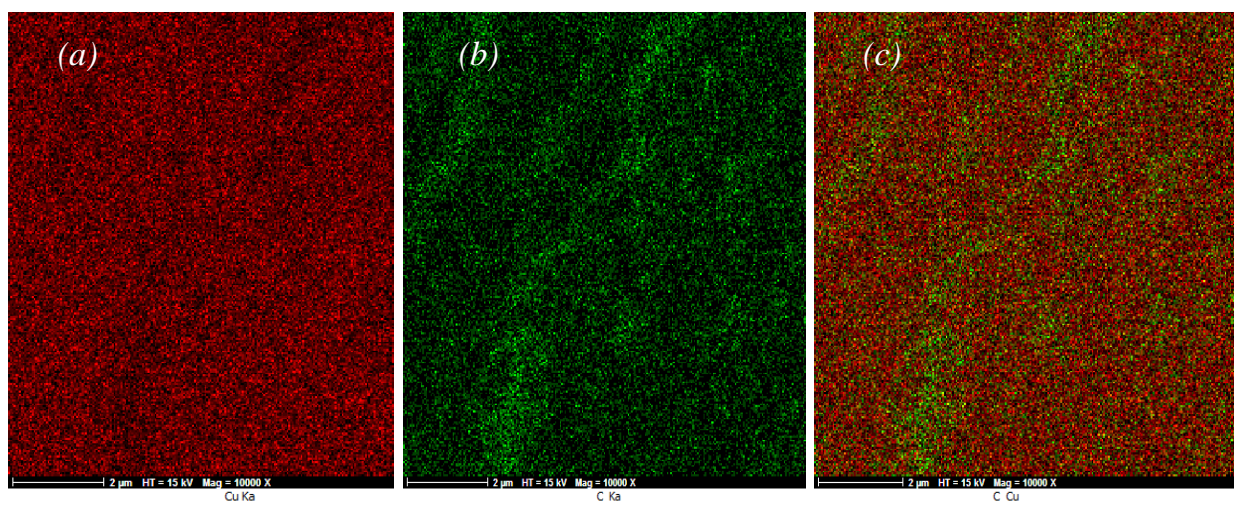

Fig. 11. MAP analysis of a) $\mathrm{Cu}, \mathrm{b}) \mathrm{C}$, and c) mixed $\mathrm{Cu}$ and $\mathrm{C}$ elements in $\mathrm{Cu}-6 \mathrm{vol} . \%$ CNT nanocomposite sample. 


\section{Conclusion}

In this study, a comparison was made between conventional and microwave sintering methods of $\mathrm{Cu}-\mathrm{CNT}$ nanocomposites. Higher relative density, electrical conductivity, micro-hardness, and bending strength were obtained by microwave sintering method. This is due to the shorter sintering time and lower sintering temperature which produce the finer microstructure proved by SEM images. This shows the high potential of microwave technique for sintering with the energy and timesaving.

The optimum amount of CNT was determined to be 4 vol. \% based on mechanical properties results.

The XRD results show that the intensity of peaks related to the sample produced in a microwave oven was lower than that of peaks for the sample produced in a conventional tube furnace, implying a finer microstructure through microwave sintering method.

The FESEM micrographs proved that the finer microstructure was acquired in microwave sintering method due to shorter heating time and higher heating rate.

\section{Acknowledgment}

The authors would like to thank INSF of Iran Contract Number of 94/sad/42699 on 9/11/2015 for complete financial support for this research work.

\section{References}

[1] A. K. Shukla, N. Nayan, S. V. S. N. Murty, K. Mondal, S. C. Sharma, K. M. George, S. R. Bakshi: Mater Charact, 84 (2013) 58-66.

[2] A. K. Shukla, N. Nayan, S. V. S. N. Murty, S. C. Sharma, P. Chandran, S. R. Bakshi, K. M. George: Mater Sci Eng, A 560 (2013) 365-37.

[3] M. J. Biercuk, M. C. Llaguno, M. Radosavljevic, J. K. Hyun, A. T. Johnson, J. E. Fischer: Appl Phys Lett, 80 (2002) 2767-2769.

[4] S. L. Ruan, P. Gao, X. G. Yang, T. X. Yu: Polymer, 44 (2003) 5643-5654.

[5] C. H. Liu, H. Huang, Y. Wu, S. S. Fan: Appl Phys Lett, 84 (2004) 4248-4250.

[6] G. D. Zhan, J. D. Kuntz, J. Wan, A. K. Mukherjee: Nat Mater, 2 (2003) 38-42.

[7] L. Kumari, T. Zhang, G. H. Du, W. Z. Li, Q. W. Wang, A. Datye, K. H. Wu: Compos Sci Technol, 68 (2008) 2178-2183.

[8] R. Sivakumar, S. Guo, T. Nishimura, Y. Kagawa: Scr Mater, 56 (2007) 265-268.

[9] S. I. Cha, K. T. Kim, S. N. Arshad, C. B. Mo, S. H. Hong: Adv Mater, 17 (2005) 1377-1381.

[10] T. Noguchi, A. Magario, S. Fukazawa, S. Shimizu, J. Beppu, M. Seki: Mater Trans, 45 (2004) 602-604.

[11]T. Laha, A. Agarwal, T. McKechnie, S. Seal: Mater Sci Eng, A 381 (2004) 249258.

[12]E. Carreño-Morelli, J. Yang, E. Couteau, K. Hernadi, J. W. Seo, C. Bonjour, L. Forro, R. Schaller: Phys Status Solidi A, 201 (2004) 53-55.

[13] S. Iijima: Nature, 354 (1991) 56-58.

[14]E. W. Wong, P. E. Sheehan, C. M. Lieber: Science, 277 (1997) 1971-1975.

[15] M. J. Treacy, T. W. Ebbesen, J. M. Gibson: Nature, 381 (1996) 678.

[16] B. I. Yakobson, C. J. Brabec, J. Bernholc: Phys Rev Lett, 76 (1996) 2511. 
[17] J. P. Lu: Phys Rev Lett, 79 (1997) 1297.

[18] K. Chu, H. Guo, C. Jia, F. Yin, X. Zhang, X. Liang, H. Chen: Nanoscale Res Lett, 5 (2010) 868

[19] M. F. Yu, B. S. Files, S. Arepalli, R. S. Ruoff: Phys Rev Lett, 84 (2000) 5552.

[20] M. F. Yu, O. Lourie, M. J. Dyer, K. Moloni, T. F. Kelly, R. S. Ruoff: Science, 287 (5453) (2000) 637-640.

[21]T. Belytschko, S. P. Xiao, G. C. Schatz, R. S. Ruoff: Phys Rev B, 65 (2002) 235430.

[22] P. G. Koppad, H. R. Aniruddha Ram, C. S. Ramesh, K. T. Kashyap, R. G. Koppad: J Alloys Compd, 580 (2013) 527-532.

[23]E. Khaleghi, M. Torikachvili, M. A. Meyers, E. A. Olevsky: Mater Lett, 79 (2012) 256-258.

[24] S. Berber, Y. K. Kwon, D. Tománek: Phys Rev Lett, 84 (2000) 4613.

[25] K. Chu, Q. Wu, C. Jia, X. Liang, J. Nie, W. Tian, G. Gai, H. Guo: Compos Sci Technol, 70 (2010) 298-304.

[26] Y. Yosida: Appl Phys, 87 (2000) 3338-3341.

[27] S. Iijima, C. Brabec, A. Maiti, J. Bernholc: Chem Phys, 104 (1996) 2089-2092.

[28]P. Jenei, E. Y. Yoon, J. Gubicza, H. S. Kim, J. L. Lábár, T. Ungár: Mater Sci Eng, A 528 (2011) 4690.

[29] Suryanarayana, C. Non-equilibrium processing of materials. Vol. 2. Elsevier, 1999.

[30] M. O. Mizuno: Ceram Trans, 111 (2001) 9.

[31]J. Ružić, D. Antanasijević, D. Božić, K. Raić: Metall Mater Engi, 20 (2014) 255260.

[32] S. G. Viswanath, M. M. Jachak: Metall Mater Eng, 19 (2013) 119-135.

[33]Z. Xie, J. Yang, X. Huang, Y. Huang: J Eur Ceram Soc, 19 (1999) 381-387.

[34]V. Viswanathan, T. Laha, K. Balani, A. Agarwal, S. Seal: Mater Sci Eng R: Reports, 54 (2006) 121-285.

[35] T. Ebadzadeh, M. Valefi: J Alloys Compd, 448 (2008) 246-249.

[36] R. Roy, D. Agrawal, J. Cheng, S. Gedevanishvili: Nature, 399 (1999) 668-670.

[37] K. Rajkumar, S. Aravindan: Wear, 270 (2011) 613-621.

[38] [W. M. Daoush, B. K. Lim, C. B. Mo, D. H. Nam, S. H. Hong: Metall Mater Eng: A, 513 (2009) 247-253.

[39] J. Cheng, D. Agrawal, Y. Zhang, R. Roy: J Mater Sci Lett, 20 (2001) 77-79.

[40] [A. D. Akinwekomi, W. C. Law, C. Y. Tang, L. Chen, C. P. Tsui: Composites, Part B, 93, (2016) 302-309.

[41]R. Casati, M. Vedani: Metals, 4 (2014) 65-83.

[42] M. Lal, S. K. Singhal, I. Sharma, R. B. Mathur: Appl Nanosci, 3 (2013) 29-35.

[43]H. T. Bui, B. T. Tran, D. Q. Le, X. T. Than, D. P. Doan, N. M. Phan: Adv Nat Sci: Nanosci Nanotechnol, 2 (2011) 015006.

[44]P. V. Trinh, T. B. Trung, N. B. Thang, B. H. Thang, T. X. Tinh, D. D. Phuong, P. N. Minh: Comput Mater Sci, 49 (2010) S239-S241.

[45] N. Chawla, Y. L. Shen: Adv Eng Mater, 3 (2001) 357-370.

[46]P. G. Koppad, H. A. Ram, K. T. Kashyap: J Alloys Compd, 549 (2013) 82-87.

[47] J. P. Tu, Y. Z. Yang, L. Y. Wang, X. C. Ma, X. B. Zhang: Tribol Lett, 10 (2001) 225-228.

[48] C. B. Lin, Z. Chang, Y. H. Tung, Y. Ko: Wear, 270 (2011) 382-394.

[49] K. Rajkumar, S. Aravindan: J Mater Process Technol, 209 (2009) 5601-5605. 
[50] M. Oghbaei, O. Mirzaee: J Alloys Compd, 494 (2010) 175-189.

[51]E. T. Thostenson, T. W. Chou: Composites, Part A, 30 (1999) 1055-1071.

[52] A. MK. Esawi, K. Morsi, A. Sayed, A. Abdel Gawad, P. Borah: J Mater Sci Eng A, 508 (2009) 167-173.

[53]W. M. Daoush: Powder Metall Met Ceram, 47 (2008) 531-537.

(c) (i) Creative Commons License

This work is licensed under a Creative Commons Attribution 4.0 International License. 